\title{
Atividades econômicas, geração de emprego e a relação com o desenvolvimento do município de Capão da Canoa (RS)
}

Juarez Camargo Borges ${ }^{1}$

Maria Raquel Caetano ${ }^{2}$

\section{Resumo}

Este artigo tem como objetivo identificar as principais atividades econômicas do município de Capão da Canoa (RS), com base no número de empregos gerados, de acordo com os dados da Relação Anual de Informações Sociais (RAIS). O estudo também buscou fazer uma análise dessas atividades, destacando a importância de cada uma delas, de forma sintetizada e hierarquizada, levantando suas potencialidades e possíveis fragilidades com o objetivo de contribuir para o desenvolvimento do município em nível regional. Este trabalho apresenta uma breve revisão bibliográfica acerca do tema proposto, uma análise das atividades econômicas do município e o quanto elas podem auxiliar no desenvolvimento da região. Diante deste estudo, pode-se concluir que o turismo é uma das principais atividades econômicas no verão, e que, no município, existem poucas atividades voltadas para essa área, seja na atividade propriamente dita ou nas que são reflexo desta, comprometendo a satisfação dos turistas que buscam o município no período do veraneio.

Palavras-chave: Litoral Norte do Rio Grande do Sul. Economia Local. Desenvolvimento Regional.

\footnotetext{
Abstract

This article aims to identify the main economic activities of the municipality of Capão da Canoa (RS), based on the number of jobs generated, according to the Annual Social Information Ratio (RAIS) data. The study also sought to make an analysis of these activities, highlighting the importance of each of them, in a synthesized and hierarchical way, raising their potentialities and possible fragilities with the objective of contributing to the development of the municipality at a regional level. This work presents a brief bibliographic review about the proposed theme, an analysis of the economic activities of the municipality and how much they can help in the development of the region. In this study, it can be concluded that tourism is one of the main economic activities in the summer, and that, in the municipality, there are few activities focused

${ }^{1}$ Mestre em Desenvolvimento Regional. Graduado em Administração. Docente da Uniasselvi Capão da Canoa. Integrante do Grupo de Pesquisas sobre o Litoral Norte. admuniasselvicapao@gmail.com

2 Doutora em Educação. Professora convidada do Programa de Pós-Graduação em Desenvolvimento Regional das Faculdades Integradas de Taquara - Faccat. caetanoraquel2013@gmail.com
} 
on this area, in the activity itself or in the ones that are a reflection of it, compromising the satisfaction of Tourists looking for the municipality during the summer period.

Keywords: Northern Coast of Rio Grande do Sul. Local Economy. Regional development.

\section{Introdução}

O litoral norte do Rio Grande do Sul e suas belezas naturais são beneficiados pela facilidade de acesso às praias, que apresentaram, nos últimos vinte anos, um desenvolvimento expressivo, tanto em sua economia, movimentada principalmente pela construção civil, quanto na sua urbanização.

Este estudo foi realizado no município de Capão da Canoa (RS), que apresentou, nos últimos anos, um considerado crescimento demográfico. É uma cidade que tem o turismo como grande impulsionador da economia local, porém merece destaque a atividade de construção civil, que emprega um grande número de pessoas durante todo o ano.

Entender o comportamento do mercado de trabalho, segundo Camargo (1996), é de grande importância para compreender o desempenho da economia regional. O volume de empregos criados, as taxas de desemprego e de aumento de produtividade, o montante de investimentos em treinamento e qualificação e muitas outras variáveis importantes, juntas, determinam o desempenho econômico de um país ou região.

Dessa forma, este artigo tem como objetivo identificar as principais atividades econômicas, com base no número de empregos gerados, de acordo com os dados de 2013 da RAIS no município de Capão da Canoa (RS) (MINISTÉRIO DO TRABALHO, 2015). O estudo também busca fazer uma análise, de forma sintetizada e hierarquizada, dessas atividades, destacando a importância de cada uma delas apontando suas potencialidades e possíveis fragilidades, com o objetivo de contribuir para a continuidade e/ou a melhoria dos estudos sobre desenvolvimento regional no litoral norte do Rio Grande do Sul.

Quanto à organização deste estudo, inicialmente, apresenta-se uma breve revisão bibliográfica acerca do crescimento das cidades do litoral norte do Rio Grande do Sul, conforme o Conselho Regional de Desenvolvimento - COREDE Litoral, destacando a cidade de Capão da Canoa e o seu processo de urbanização. Por fim, evidenciam-se as principais atividades econômicas do município.

\section{0 crescimento das cidades}

O crescimento das cidades impacta em inúmeros problemas sociais, econômicos e ambientais, principalmente em áreas com ocupações ilegais e sem a devida estrutura para viver com qualidade. Portanto, é necessária a consciência política sobre a "urbanização da pobreza", sendo que essa consciência se fez presente na criação, em 2003, do Ministério das Cidades. É importante destacar que "[...] aque- 
las cidades que buscam oferecer a desregulamentação como vantagens tiveram seu crescimento limitado pela própria queda na qualidade de vida" (PNDU, 2004, p. 19). Em algumas cidades, pode-se perceber a falta de políticas públicas fiscalizadoras, pois é visível o crescimento desordenado.

É neste contexto que, segundo a Política Nacional de Desenvolvimento Urbano (PNDU, 2004), foi criado e estruturado o Ministério das Cidades, levando em consideração a reunião das áreas mais relevantes (do ponto de vista econômico e social) e estratégicas (sustentabilidade ambiental e inclusão social) do desenvolvimento urbano.

Para o PNDU (2004, p. 36), "[...] a cidade não é neutra e pode ser vista como uma força ativa, uma ferramenta eficaz para gerar empregos e renda e produzir desenvolvimento econômico". Essa nova tipologia do entendimento da formação das cidades deve estar pautada em atender às demandas comerciais de transportes, armazenagem, reparações mecânicas, para fomentar o desenvolvimento econômico e as variáveis relacionadas à infraestrutura da cidade, como habitação, saúde, cultura, finanças, educação geral e profissional. Portanto, cabe à "[...] política urbana revelar as cidades para a ação governamental e destacar a sua importância para o desenvolvimento de toda uma região e até do País como um todo" (PNDU, 2004, p. 37). Essa é a função da nova tipologia das cidades, em elaboração no âmbito da Política Nacional de Desenvolvimento Urbano.

Conforme a Constituição Federal, no artigo 182, as cidades com mais de vinte mil habitantes ficam obrigadas a elaborar um Plano Diretor. Esse plano "[...] é um documento da natureza técnica e política e tem por objetivo direcionar o crescimento físico-territorial e socioeconômico dos núcleos urbanos do município" (BONAMENTE; SOUZA, 2012, p. 21). O plano diretor deve conter, segundo os autores, documentos de informação e análise (diagnóstico, relatórios, mapas), documentos de orientação (definição de políticas, diretrizes, estratégias), documentos operativos (planos de ação, projetos) e documentos normativos (projetos de lei), que formam um conjunto de leis ou códigos que tratam de assuntos concernentes à vida urbana, como ordenamento do território, localização das atividades, largura das ruas e regras para os loteamentos e construções.

Segundo Bonamente e Souza (2012), o objetivo do plano diretor é direcionar o desenvolvimento da cidade de forma a garantir a qualidade de vida da população. Com base no plano diretor, o crescimento da cidade não está vinculado aos interesses políticos, particulares ou imediatistas, possibilitando o crescimento ordenado da cidade com visão de longo prazo. O desenvolvimento regional depende de "[...] repensar o desenvolvimento urbano e regional brasileiro e implica em elaborar um projeto de médio e longo prazo que tenha como meta a redução das desigualdades regionais e sociais" (PNDU, 2004, p. 35).

De acordo com o desenvolvimento da cidade, o plano diretor deve ser revisado e ampliado de maneira formal, incluindo atividades que até então não existiam na região. Por isso, Bonamente e Souza (2012, p. 79) dizem que o desenvolvimento regional deve considerar "[...] o trinômio formado pelo crescimento econômico, pela justiça social e pela necessária prudência ecológica, estabelecendo metas seguras 
para o desenvolvimento sustentável". O crescimento da cidade deve respeitar o plano diretor, que regulamenta o uso e a ocupação do solo, principalmente em relação aos aspectos ambientais.

\subsection{O litoral norte do Rio Grande do Sul e o crescimento das cidades}

O litoral norte tem sua região delimitada, ao sul, pelo município de Pinhal, em função de sua formação geológica, relevo, bacia de drenagem e limites políticos, até os limites de Torres. Segundo dados do COREDE Litoral (2015), a região do litoral norte é composta por 21 municípios, entre eles Capão da Canoa. A ocupação dessa região é datada de 1732, destacando-se a colonização dos Açores, de Portugal e de Laguna, através da concessão de sesmarias e datas de terras, sendo que a característica da economia se dava pela agricultura, pela pecuária e pela pesca. Souza (2013) avalia que a falta de investimento em estradas dificultava o acesso ao litoral, e a ocupação e urbanização foram mais intensas a partir de 1930, com investimentos do governo do estado em redes de água e de energia elétrica. A Tabela 1, inserida na próxima página, apresenta a população do litoral norte de 2000 a 2010.

Os municípios com maior número de habitantes do litoral são Capão da Canoa, Tramandaí, Osório e Torres (Tabela 1). Pode-se destacar que esses municípios "[...] possuem influência sobre os demais, recebendo mais investimentos e oferecendo melhor estrutura, conferindo-lhes maior importância no cenário regional" (RAMOS, 2014, p. 16). Os dados do censo demográfico do Estado apresentam um aumento na taxa de crescimento populacional, considerando o período de 2000-2010, de apenas 4,97\%, enquanto o litoral norte apresentou taxas elevadas de crescimento populacional, diferenciadas do restante do Estado, registrando um crescimento de 21,64\% (IBGE, 2014).

A atividade turística e o processo de urbanização dos municípios costeiros do litoral norte do Rio Grande do Sul, somados às emancipações políticas, e os investimentos de empresas no litoral norte, associados aos investimentos do Poder Público, por meio de obras, como a duplicação da rodovia BR 101, a construção da Rota do Sol - ERS 486 e a Estrada do Mar - ERS 389, contribuíram fortemente para o processo de urbanização da região. Assim, os veranistas de Porto Alegre e Caxias do Sul, na Serra Gaúcha, começaram suas construções residenciais no litoral norte a partir do ano de 1982, segundo Scheffer (2010). 
Tabela 1 - População Litoral Norte por municípios em 2000-2010

\begin{tabular}{lrrr}
\hline \multicolumn{1}{c}{ Município } & $\begin{array}{c}\text { População total } \\
\mathbf{2 0 0 0}\end{array}$ & $\begin{array}{c}\text { População total } \\
\mathbf{2 0 1 0}\end{array}$ & $\begin{array}{c}\text { Variação } \\
\mathbf{\%}\end{array}$ \\
\hline Arroio do Sal & 5.273 & 7.740 & 46,79 \\
Balneário Pinhal & 7.452 & 10.856 & 45,68 \\
Capão da Canoa & 30.498 & 42.040 & 37,85 \\
Capivari do Sul & 3.107 & 3.890 & 25,20 \\
Caraá & 6.403 & 7.312 & 14,20 \\
Cidreira & 8.882 & 12.668 & 42,63 \\
Dom Pedro de Alcântara & 2.636 & 2.550 & $-3,26$ \\
Imbé & 12.242 & 17.670 & 44,34 \\
Itati & & 2.584 & \\
Mampituba & 3.106 & 3.003 & $-3,32$ \\
Maquiné & 7.304 & 6.905 & $-5,46$ \\
Morrinhos do Sul & 3.533 & 3.182 & $-9,93$ \\
Mostardas & 11.658 & 12.124 & 4,00 \\
Osório & 36.131 & 40.906 & 13,22 \\
Palmares do Sul & 10.854 & 10.969 & 1,06 \\
Terra de Areia & 11.453 & 9.878 & $-13,75$ \\
Torres & 30.880 & 34.656 & 12,23 \\
Tramandaí & 31.040 & 41.585 & 33,97 \\
Três Cachoeiras & 9.523 & 10.217 & 7,29 \\
Três Forquilhas & 3.239 & 2.914 & $-10,03$ \\
Xangri-lá & 8.197 & 12.434 & 51,69 \\
Litoral Norte & $\mathbf{2 4 3 . 4 1}$ & $\mathbf{2 9 6 . 0 8 3}$ & $\mathbf{2 1 , 6 4}$ \\
Rio Grande do Sul & $\mathbf{1 0 . 1 8 7 . 7 9 2}$ & $\mathbf{1 0 . 6 9 3 . 9 2 9}$ & $\mathbf{4 , 9 7}$ \\
Brasil & $\mathbf{1 6 9}$ & & $\mathbf{1 2 , 3 6}$ \\
\hline & & &
\end{tabular}

Fonte: IBGE (2014). Adaptado pelos autores.

Segundo dados da Famurs (2014), outro investimento importante para o processo de urbanização do litoral foi a construção da Estrada do Mar, ERS -389, em 1980, fazendo a ligação dos municípios de Osório e Torres, facilitando o acesso às praias. É importante ressaltar que o município de Capão da Canoa, naquele tempo, pertencia à cidade de Osório, sendo emancipado em 1982, e Xangri-lá foi emancipado em 1992 de seu município de origem, Capão da Canoa.

Pode-se perceber uma diferenciação ambiental, social e econômica bastante desigual entre os municípios do litoral norte. Ramos (2014) destaca-os como município praiano e não praiano, principalmente em função da natureza da região, refletin- 
do nas suas atividades econômicas.

A expansão demográfica de Capão da Canoa fez crescer a demanda por residências na praia. Logo a indústria da construção civil, na cidade de Capão da Canoa, impulsionou a implantação de uma série de atividades relacionadas ao comércio e a serviços complementares, ampliando as opções de trabalho e atraindo população permanente para a região (RAMOS, 2014). A Tabela 2 mostra a escolaridade da população de 2000 a 2010.

Tabela 2 - Escolaridade da população 2000-2010

\begin{tabular}{lrc}
\hline & Ano 2000 & Ano 2010 \\
\hline Fundamental incompleto/analfabeto & $8 \%$ & $4,5 \%$ \\
Fundamental incompleto & $57,5 \%$ & $40,2 \%$ \\
Fundamental completo & $15,3 \%$ & $21,1 \%$ \\
Médio completo & $13,9 \%$ & $24,1 \%$ \\
Superior completo & $5,3 \%$ & $10,1 \%$ \\
TOTAL & $100 \%$ & $100 \%$ \\
\hline
\end{tabular}

Fonte: IBGE (2014). Adaptado pelos autores.

Em relação aos índices de educação da população em Capão da Canoa, observa-se uma concentração de pessoas com ensino fundamental incompleto/completo, pois $61,3 \%$ encontram-se nessa classe, seguido de $24,1 \%$ com ensino médio, e apenas 10,1\% com ensino superior. Essa última apresenta um aumento relevante, quando comparada ao ano de 2000, em que apenas 5,3\% da população apresentava ensino superior. Sobre a qualificação profissional da população, pode-se dizer que muitas pessoas ainda não conseguiram completar seus estudos básicos, sendo essa uma característica das pessoas que trabalham no setor que mais emprega na cidade - a construção civil - em que a escolaridade, normalmente, é baixa.

Sobre o Índice de Desenvolvimento Socioeconômico (IDESE) do litoral norte, Ramos (2014) destaca que esse índice não leva em consideração outros aspectos relevantes no conceito de qualidade de vida da população dessa região, como "[...] segurança pública, mobilidade urbana, lazer e empregabilidade". De acordo com Ramos, esses aspectos apontam para a realidade do litoral norte em relação ao Estado, com algumas fragilidades.

\section{2 processo de urbanização em Capão da Canoa}

"O litoral norte é uma região riquíssima sob o ponto de vista ambiental" (SOUZA, 2013). As características peculiares da região e a questão ambiental devem ser analisadas no momento da ocupação e da urbanização dessa região. Para isso, tem-se a Constituição do Rio Grande do Sul de 1989 e a Lei de Crimes Ambientais no 9.605 de 1998, que estipulam penas e sanções ao crime ambiental. Com a mesma impor- 
tância, tem-se ainda o Estatuto das Cidades, que estabelece diretrizes da política urbana.

O litoral norte tem como principal atividade econômica o turismo. Scheffer (2010) destaca que o turismo, por sua vez, acabou por desenvolver diversos produtos, como, por exemplo, os vários empreendimentos imobiliários, a fim de atender os veranistas que buscam a qualidade de vida nas praias gaúchas. Porém, esse desenvolvimento acabou por prejudicar a fauna e a flora da região.

No desenvolvimento da cidade de Capão da Canoa, destacam-se os principais responsáveis pela transformação do espaço urbano, sendo eles os investidores, os construtores e os corretores de imóveis. O produto mais divulgado e comercializado no litoral são os condomínios fechados, diante do custo/benefício, caracterizado principalmente pela segurança e a infraestrutura oferecida nesses empreendimentos (SOUZA, 2013).

O processo de urbanização de Capão da Canoa, segundo Souza (2013), está relacionado ao desenvolvimento econômico da construção civil. A dinâmica da urbanização seguiu uma direção para atender à demanda por residências para uma classe social de maior poder aquisitivo, mas cabe destacar que o setor demandou também mão de obra para trabalhar na construção civil. Isso acabou atraindo muitas pessoas para a cidade, contribuindo para a formação do perfil de urbanização da cidade, deixando uma parte dela com alta valorização imobiliária, muitas vezes por especulação, com maiores investimentos em infraestrutura pública, e outra parte sem muitos atrativos comerciais. Nesses locais de baixo valor agregado, concentram-se a população de renda inferior, principalmente os trabalhadores da construção civil.

O cenário do mercado da construção civil no litoral teve uma grande evolução nestes últimos 10 anos, com grandes empreendimentos e, consequentemente, grandes empreendedores, juntamente com outros profissionais do ramo da construção civil (SESSEGOLO, 2014). Podem-se citar como componentes do desenvolvimento da região do litoral norte a força empreendedora de algumas pessoas que acreditaram no mercado da construção civil e aplicaram todas as suas crenças e investimentos na criação de novas empresas, sendo que novos postos de trabalho foram criados, dando, assim, uma identidade muito evidente de qual setor está à frente da economia da cidade e da região. De acordo com o presidente do Sinducon-RS, "Hoje o maior empregador aqui no litoral é a construção civil" (SESSEGOLO, 2014).

Os impactos na sociedade podem ser percebidos nas esferas econômica, ambiental e social. Este último é percebido pela segregação urbana provocada nas cidades de Capão da Canoa e Xangri-lá, pois a limitação dos espaços, com a construção dos muros, deixa evidente a divisão entre aqueles que residem no condomínio e os demais moradores da cidade.

No aspecto econômico, o processo de urbanização nestas cidades alavancou oportunidades de serviços como os de engenharia e arquitetura, além da expressiva geração de empregos na construção civil e demais serviços ligados ao setor. Além disso, fomentou o comércio local, principalmente os de materiais de construção, para o fornecimento de materiais para grandes construções, da fundação ao acabamento e decoração. 
Especificamente sobre a geração de emprego, tem-se o exemplo do Condomínio Xangri-lá Villas Resort que, atualmente, para seu funcionamento diário, emprega em torno de 150 funcionários, a citar os empregos diretos: doze zeladores; seis jardineiros, para a manutenção das áreas de uso comum; e quatro encarregados de serviços gerais. Com relação aos empregos indiretos, o condomínio conta com mais de 130 pessoas, as quais prestam serviços terceirizados de limpeza e segurança privada ao condomínio durante todo o ano. Outro exemplo é o Condomínio Condado de Capão, que gera dezessete empregos diretos e conta com mais de trinta pessoas envolvidas com serviços terceirizados para segurança e jardinagem do condomínio durante o ano todo.

Com o mesmo grau de importância, destacam-se os impactos ambientais inerentes à construção e à urbanização de áreas com características naturais do litoral. O que se percebe é uma grande modificação da paisagem natural, da fauna e da flora, pois os campos e os animais nativos perderam espaço para as grandes e luxuosas construções desses condomínios.

Diante dos impactos abordados aqui, cabe ressaltar que os empreendimentos foram importantes para o desenvolvimento regional nos aspectos econômicos, sociais e com uma série de provocações às questões ambientais. Dessa forma, cabe incentivar um estudo sobre o impacto que esses empreendimentos provocam na cidade em relação ao meio ambiente, à cultura da cidade e à vida das pessoas (SOUZA, 2013). A autora (2013) ainda adverte que, diante da vulnerabilidade ambiental de Capão da Canoa e Xangri-lá, é importante mencionar que o Poder Público deve pensar que, futuramente, a cidade vai demandar mais escolas e postos de saúde maiores, e o município pode não dispor de terrenos para atender a essa demanda. Além disso, é importante levar em consideração o fornecimento de água e o tratamento de esgoto, que é uma questão importante a ser observada, ou seja, até que ponto a Lagoa dos Quadros suportará o recebimento dos dejetos.

\subsection{0 município e seus aspectos históricos, demográficos e econômicos}

A ocupação do município de Capão da Canoa teve seu surgimento a partir de 1933 como $6^{\circ}$ Distrito de Osório, denominado como "Vila de Capão da Canoa", e assim permaneceu por trinta anos, quando então se deu a emancipação do município, com a Lei $n$ o 7.638, de 12 de abril de 1982. Naquele momento, o município contava inicialmente com 23 balneários, possuindo um raio de 30 quilômetros de praia.

Atualmente, encontra-se no município uma estrutura totalmente diferente da que se observava em seu marco inicial. Hoje, a cidade conta com onze balneários, com uma extensão de 19,1 quilômetros para norte e sul, divididos em quatro distritos: Capão da Canoa - sede, Capão Novo, Arroio Teixeira e Curumim, formados por solo bastante arenoso, podendo ser observada a presença de algumas dunas naturais nos balneários de Praia do Barco, Capão Novo e Arroio Teixeira.

O município de Capão da Canoa é constituído de um patrimônio natural muito agradável, principalmente no verão, pois é nessa estação que o município recebe muitos visitantes. Constitui-se de uma planície costeira no litoral norte do Rio Grande 
do Sul. Segundo o Censo Demográfico do IBGE, a população de Capão da Canoa, nos últimos trinta anos, apresentou um crescimento, registrando, em 1991, uma população de 25.000 mil habitantes, seguindo de 32.000 no ano de 2000 e, atualmente, compõe-se de 42.040 habitantes, conforme pesquisa realizada em 2010 pelo IBGE.

Os demais dados municipais encontram-se no Quadro 1, segundo o Atlas do Desenvolvimento Humano no Brasil (2015). Alguns desses dados são importantes sobre a caracterização do território do município de Capão da Canoa (RS).

\section{Quadro 1 - Dados Municipais}

Área: $94,45 \mathrm{~km}^{2}$

IDHM 2010: 0,743

Faixa do IDHM: Alto (IDHM entre 0,700 e 0,799)

População (Censo 2010): 42.040 hab.

Densidade demográfica: 445,18 hab/ $\mathrm{km}^{2}$

Ano de instalação: 1982

Microrregião: Osório

Mesorregião: Metropolitana de Porto Alegre

Fonte: Atlas do Desenvolvimento Humano no Brasil (2015).

No entanto, estima-se que a população do município esteja por volta dos 45.000 (quarenta e cinco mil) habitantes. Sabe-se que esse número aumenta consideravelmente nos períodos de veraneio, compreendidos entre dezembro a março, quando a marca chega a 600.000 (seiscentos mil) habitantes, entre visitantes e moradores fixos.

Os fatores que justificam o grande número de visitantes no município são, dentre outros, principalmente o clima, com temperaturas agradáveis, mesmo em períodos de temperaturas altas; a grande faixa costeira, utilizada para banho, pesca, prática de surfe, e a estrutura, composta por belo calçadão. Isso possibilita a prática de esportes, como caminhada, ciclismo, vôlei e futebol.

Capão da Canoa apresenta uma característica clara, que é a migração, verificada principalmente durante as temporadas de veraneio. As pessoas acabam permanecendo ali e, ao longo do ano, não encontrando emprego fixo nem moradia, acabam por aumentar a favelização do município.

Em um estudo recente, Ramos (2014) revelou os motivos que levaram as pessoas a se mudarem para Capão da Canoa. Dos pesquisados, $47 \%$ destacaram a opção de ter um novo emprego, 25\% destacaram a qualidade de vida, e 19,6\% destacaram como motivo ficar junto à família. Esses resultados mostram que muitas pessoas procuram o litoral, especificamente o município de Capão da Canoa, pelas oportunidades de emprego e qualidade de vida. A expansão demográfica de Capão da Canoa fez crescer a demanda por residências na praia. Logo, a indústria da construção civil na cidade de Capão da Canoa impulsionou a implantação de uma série de atividades relacionadas ao setor de comércio e serviços complementares, ampliando as opções de trabalho e atraindo a população permanente para a região (RAMOS, 2014). 
Tabela 3 - População por gênero, rural/urbana - Capão da Canoa (RS)

\begin{tabular}{lrr}
\hline \multicolumn{1}{c}{ População } & População 2000 & População 2010 \\
\hline Homens & 15.099 & 20.616 \\
Mulheres & 15.399 & 21.424 \\
Urbano & 30.334 & 41.787 \\
Rural & 164 & 253 \\
TOTAL & $\mathbf{3 0 . 4 9 8}$ & $\mathbf{4 2 . 0 4 0}$ \\
\hline
\end{tabular}

Fonte: IBGE (2014).

Conforme dados da Tabela 3, uma característica propulsora de emprego em Capão da Canoa é que a cidade se concentra no espaço urbano, visto que a população rural é mínima. A composição da população ocupada na cidade, economicamente ativa, é de $70,8 \%$, seguida de $23,3 \%$ inativa e 5,9\% economicamente ativa, mas desocupada, registrando uma menor taxa em relação ao ano de 2000 (IBGE, 2014).

No município, identifica-se a atividade de turismo como grande impulsionadora da economia regional. Porém merece destaque a atividade de construção civil, que emprega o maior número de pessoas, capaz de fomentar as finanças do município durante todo o ano. Segundo dados do Atlas do Desenvolvimento Humano no Brasil (2015), 1,44\% das pessoas empregadas no município trabalhava no setor agropecuário, 5,23\%, na indústria de transformação; 22,38\%, no setor de construção; $0,72 \%$, nos setores de utilidade pública; $19 \%$, no comércio, e $48 \%$, no setor de serviços.

\section{0 município de Capão da Canoa e as atividades econômicas}

Para realização desta análise, tomar-se-á como objeto de estudo a estrutura econômica do município de Capão da Canoa, analisando suas características e as principais atividades econômicas, bem como a dinâmica do mercado de trabalho, com base em dados fornecidos pela Relação Anual de Informações Sociais (RAIS) do ano de 2013, destacando as principais atividades pelos Quocientes Locacionais ${ }^{3}$ (QLS).

O sistema de North destacado por Paiva (2004) permite distinguir dois tipos de atividade econômica, regional ou local: 1) as atividades propulsivas são aquelas responsáveis pelo ingresso inicial de recursos monetários no território. São as atividades pelas quais as regiões se vinculam à nação; 2) as atividades reflexas são aquelas que se voltam para o atendimento das demandas locais. Elas dependem do

\footnotetext{
${ }^{3}$ Conforme Paiva (2004), a dinâmica de um território e sua região economicamente consistente deve partir do perfil de especialização e exportações, é necessário delimitar um indicador que diferencie as atividades voltadas para o mercado interno das atividades propulsivas. Este indicador, desenvolvido por Hildebrand e Mace (1950), é o Quociente Locacional que, segundo North (1955, p. 300/301), "[...] compara a concentração de emprego de uma determinada indústria em uma área (a economia objeto) com outra área (a economia de referência)".
} 
ingresso inicial para emergirem, mas, ao emergirem, elas se retroalimentam, multiplicam-se.

A análise de um território, levando em conta o QL das atividades econômicas, considera que um QL acima de 1,00 (um) atende moradores e visitantes, como o exemplo de Capão da Canoa, uma cidade turística. Para o uso deste indicador, Paiva (2004) destaca a necessidade de determinar a economia de referência, neste caso da região do Litoral Norte gaúcho, toma-se o Rio Grande do Sul. Nesse sentido, quanto maior for o QL, maior a importância dessa atividade (incluindo atividades diretas ou indiretas) no contexto do desenvolvimento econômico do território.

A identificação e hierarquização das cadeias propulsivas se baseiam em três critérios básicos, conforme (PAIVA, 2004, p. 50):

- número de empregos gerados na atualidade;

- perspectivas de mercado à frente da competitividade da economia regional para atender mercados em expansão;

- capacidade dos agentes e sistemas locais para o enfrentamento dos desafios e demandas de inovação tecnológica, gerencial e produtiva da cadeia.

Neste item, será apresentada uma breve análise das principais atividades econômicas, aquelas que apresentam maior número de empregos, bem como sua classificação em atividade propulsiva ou reflexa da atividade principal, com objetivo de destacar as atividades potenciais da economia local e sua importância para o desenvolvimento regional.

\subsection{Administração Pública}

A principal atividade deste grupo é a administração pública em geral. Entre as atividades de administração pública, cabe destacar a relação de dependência do município de Xangri-lá em relação a alguns serviços de gestão pública, pois algumas atividades estão concentradas em Capão da Canoa, que visa atender às demandas dos dois municípios.

\section{Quadro 2 - Emprego na Administração Pública}

\begin{tabular}{|l|c|c|c|c|}
\hline $\begin{array}{c}\text { Síntese da } \\
\text { atividade }\end{array}$ & $\begin{array}{c}\text { Capão da } \\
\text { Canoa }\end{array}$ & $\begin{array}{c}\text { No Empregos } \\
\text { Capão da Canoa }\end{array}$ & $\begin{array}{c}\text { No Empregos } \\
\text { RS }\end{array}$ & Classificação \\
\hline $\begin{array}{l}\text { Administração } \\
\text { Pública }\end{array}$ & 1,12 & 1.642 & 321.351 & G. Propulsiva $^{4}$ \\
\hline
\end{tabular}

Fonte: Ministério do Trabalho (2014). Adaptado pelos autores.

Dentre os serviços públicos que atendem aos municípios, citam-se a Secretaria da Fazenda do Estado, cujo escritório sede é em Capão da Canoa; o Fórum, que também tem sua comarca em Capão da Canoa; todos os serviços da justiça comum,

\footnotetext{
${ }^{4}$ Atividades integralmente financiadas por dispêndio governamental denominada G. Propulsivas. As siglas derivam da notação convencional para Exportação (X) e Gasto Governamental (G). (PAIVA, 2015).
} 
que são para atender à demanda de ambos, assim como a Justiça do Trabalho; o Tabelionato e Registro de Imóveis; os serviços prestados pelas agências da Caixa Econômica Federal, como o encaminhamento para saque do FGTS (Fundo de Garantia do Tempo de Serviço) e o financiamento habitacional. Este último contempla apenas uma agência no município, que apresenta uma carência de pessoal em sua estrutura para atender à demanda da sociedade. Portanto, a atividade de administração pública que envolve serviços para um grande número de pessoas não apresenta um expressivo número de empregos gerados, visto que alguns serviços podem ser considerados precários no atendimento à população.

\subsection{Turismo e Lazer}

Nesta cadeia denominada Turismo e Lazer, podem-se verificar duas principais atividades relacionadas ao lazer e aos estabelecimentos hoteleiros. Cabe destacar que, mesmo sendo um município com potencial turístico, Capão da Canoa tem, nesta atividade, poucas pessoas empregadas. Pode-se concluir, então, que essa não é uma atividade muito explorada, embora a região do litoral apresente esse potencial. Esta cadeia é normalmente movimentada principalmente pelo turismo eventual, e este não é o alvo de investimento das empresas locais, pois o foco é o turista permanente, que pode ser representado, de acordo com Paiva (2015, p. 103), "[...] pelo aposentado ou rentista que opta por domiciliar-se em um território distinto daquele em que trabalhou e ou que lhe proporcione a renda atual por avaliar que o novo domicílio Ihe proporciona uma qualidade de vida superior". E essa classificação de turista, o que acaba por adquirir seu imóvel próprio, é que, por sua vez, fomenta a atividade da construção civil, que é amplamente explorada não só no município como também em outros municípios do Litoral Norte.

\section{Quadro 3 - Emprego em Turismo e Lazer}

\begin{tabular}{|c|c|c|c|c|}
\hline $\begin{array}{c}\text { Síntese da } \\
\text { atividade }\end{array}$ & $\begin{array}{c}\text { Capão da } \\
\text { Canoa }\end{array}$ & $\begin{array}{c}\text { No Empregos } \\
\text { Capão da Canoa }\end{array}$ & $\begin{array}{c}\text { No Empregos } \\
\text { RS }\end{array}$ & Classificação \\
\hline Turismo \& Lazer & 2,94 & 397 & 29.558 & TrS Propulsiva $^{5}$ \\
\hline
\end{tabular}

Fonte: Ministério do Trabalho (2014). Adaptado pelos autores.

Em outro estudo realizado por Pinent (2015, p. 52), ao relacionar a empregabilidade do Litoral Norte nas atividades relacionadas ao turismo, "[...] demonstra que o turismo movimenta a economia local [...]", porém não se destaca nem como os maiores QL, nem como o de maior empregabilidade. É possível verificar, na região

\footnotetext{
${ }^{5} \mathrm{O}$ símbolo TrS busca resgatar o fato desta renda advir de transferências privadas, associadas à aquisição de serviços no território por turistas (PAIVA, 2015, p. 102-103). Destaca quatro tipos de turistas: 1) turismo de lazer, 2) turismo de compras e serviços, 3) turismo de negócio e 4) turismo permanente.
} 
do litoral e, especificamente, em Capão da Canoa, a deficiência em atividades ligadas ao turismo ou a atividades ligadas ao veraneio. Conforme afirma Moraes (2003), para o desenvolvimento regional local de determinado território, é preciso identificar as potencialidades endógenas. Dessa forma, é preciso desenvolver as comunidades locais de forma estratégica, de modo a potencializar o desenvolvimento regional local. Atualmente, poucas atividades desenvolvidas na cidade estão voltadas para o turismo.

Considerando essa uma atividade propulsiva, é preciso criar uma identidade para a cidade, de forma que explore não somente as belezas naturais, mas também toda uma estrutura pensada para atender e atrair os turistas, como, por exemplo, a qualidade do atendimento no comércio em geral e na prestação de serviço, sendo essa característica um fator de atração ao turista permanente ou eventual e, assim, manter o desenvolvimento da região por meio do turismo.

De acordo com Paiva (2015), o tamanho e o crescimento da economia regional dependem do crescimento de sua atividade propulsiva, pois as atividades não são independentes e se relacionam uma com as outras. Será necessária a união de esforços entre empresas do setor para o desenvolvimento de estratégias para melhor exploração das atividades relacionadas ao turismo no município e em todo litoral.

\subsection{Construção Civil}

Neste grupo, é possível identificar as atividades ligadas à construção civil, que pode ser considerada propulsiva, bem como os demais produtos e serviços característicos da função, desde a fundação até o acabamento, também relacionada a reformas e à manutenção de imóveis. Essas atividades podem ser consideradas como reflexo da atividade principal e são responsáveis por 3.763 empregos. As principais atividades deste grupo são edificações e incorporação (compra e venda) de imóveis, diretamente ligadas à construção civil. Na sequência, cabe destacar as atividades de condomínios e administração de imóveis prediais, duas atividades importantes de serviços ligadas às principais atividades econômicas no município.

\section{Quadro 4 - Emprego na Construção Civil}

\begin{tabular}{|c|c|c|c|c|}
\hline $\begin{array}{c}\text { Síntese da } \\
\text { atividade }\end{array}$ & $\begin{array}{c}\text { Capão da } \\
\text { Canoa }\end{array}$ & $\begin{array}{c}\text { No Empregos } \\
\text { Capão da Canoa }\end{array}$ & $\begin{array}{c}\text { No Empregos } \\
\text { RS }\end{array}$ & Classificação \\
\hline Construção Civil & 2,41 & 3.763 & 342.607 & Propulsiva $^{6}$ \\
\hline
\end{tabular}

Fonte: Ministério do Trabalho (2014). Adaptado pelos autores.

\footnotetext{
${ }^{6} \mathrm{O}$ sistema de North nos identificar na atividade econômica regional ou local, quais são as atividades propulsivas, que são aquelas responsáveis pelo ingresso inicial de recursos monetários no território. São as atividades pelas quais as regiões se vinculam à nação. Há dois tipos de atividades propulsivas: 1 ) atividades que geram bens tradables (transportáveis), que são "exportados" para fora da região. 2) atividades que geram (bens e) serviços não tradables e não-ubíquos, pois a escala mínima eficiente é demasiado elevada para serem ofertados em espaços rurais e cidades de pequeno porte. No primeiro caso, a renda primária ingressa no território por depósitos bancários realizados pelo comprador. No segundo caso, é o próprio comprador que se dirige ao território para adquirir o bem ou serviço (PAIVA, 2015).
} 
A construção civil é a principal atividade econômica das cidades em destaque neste estudo, e o produto condomínio horizontal fechado provoca diversos impactos também no meio ambiente, no modelo de urbanização e na vida das pessoas. Modifica, principalmente, a paisagem natural do litoral entre o mar e a lagoa, devido à ocupação urbana de áreas rurais, com grandes e luxuosas residências. Conforme Sessegolo (2014), o cenário do mercado da construção civil no litoral teve uma grande evolução e, nestes últimos 10 anos, grandes empreendimentos e, consequentemente, grandes empreendedores surgiram, juntamente com outros profissionais do ramo da construção civil.

No litoral norte do Rio Grande do Sul, principalmente nas cidades de Xangri-lá e Capão da Canoa, os condomínios residenciais horizontais surgiram inicialmente a partir de 1990, em Xangri-lá, e, no ano de 2012, registrava-se o número de nove condomínios em Capão da Canoa e dezoito em Xangri-lá. Os empreendimentos não estão limitados a uma localização pré-determinada, já que em toda extensão territorial dos municípios encontram-se tais modelos de ocupação, quer à beira-mar, quer à beira da lagoa (SOUZA, 2013).

Com o dinamismo da construção civil, pode-se perceber que, no município, cresceu a demanda por outras atividades, despertando o interesse dos empreendedores e de outros profissionais em investir no município. Nesse grupo, encontra-se também a atividade de comércio de materiais de construção, que ocupa 608 funcionários, um reflexo da construção civil no município.

Conforme dados de 2013 da Junta Comercial do Rio Grande do Sul, 16 (dezesseis) empresas de materiais de construção disputavam o mercado em 2000, e, em 2010, já disputavam a preferência do consumidor 35 (trinta e cinco) empresas do segmento (RAMOS, 2014).

Entre as atividades classificadas como de consumo reflexo ${ }^{7}$ da construção civil, encontram-se as de logística, madeiras e mobiliários, as quais podem ser consideradas como integrantes da cadeia da construção civil, seja para o fornecimento de madeiras e a fabricação de artigos de madeiras, bem como a fabricação de móveis sob medida e mobiliários em geral.

Já na atividade de logística, encontram-se atividades de transporte, como suporte à atividade principal da construção civil. Nessa atividade, encontram-se a de malotes e entrega. Portanto, as duas cadeias são fomentadas pela atividade central do município.

\subsection{Produto e serviços para população local e/ou destinados ao Turismo e Lazer}

Neste grupo, identificam-se as atividades reflexas. As principais são comércio de artigos do vestuário e calçados, comércio de alimentos e bebidas, como os res-

\footnotetext{
${ }^{7}$ Atividades de Consumo Reflexo, conforme Paiva (2004, p. 117): "As atividades que respondem às demandas derivadas das atividades principais, consideradas propulsivas, são denominadas de dois tipos: aquelas destinadas a atender a demanda do consumidor local, denominadas como 'consumo reflexo', e aquelas voltadas ao atendimento de demandas dos mais distintos agentes sediados localmente, sejam eles consumidores, empresas ou órgãos governamentais são denominados de 'Genérico Reflexas'”.
} 
taurantes e lanchonetes, e produtos farmacêuticos, pois essas atividades são as que apresentam maior número de empregos gerados, de acordo com a forte demanda da população local, bem como aquela demanda do turista/veranista por produtos em geral.

Essas atividades têm uma grande importância, pois se encarregam de oferecer produtos, para atender ao grande número de visitantes durante o período de veraneio e, também,os moradores durante o restante do ano.

\section{Quadro 5 - Emprego no Comércio de Produtos e Serviços}

\begin{tabular}{|l|c|c|c|c|}
\hline $\begin{array}{c}\text { Síntese da } \\
\text { atividade }\end{array}$ & $\begin{array}{c}\text { Capão da } \\
\text { Canoa }\end{array}$ & $\begin{array}{c}\text { No Emp. } \\
\text { Capão da Canoa }\end{array}$ & $\begin{array}{c}\text { No Emp. } \\
\text { RS }\end{array}$ & Classificação \\
\hline $\begin{array}{l}\text { Produtos e Serviços } \\
\text { para Famílias e/ou } \\
\text { Turismo \& Lazer }\end{array}$ & 1,51 & 4.491 & 649.175 & $\begin{array}{c}\text { Consumo } \\
\text { Reflexo }\end{array}$ \\
\hline
\end{tabular}

Fonte: Ministério do Trabalho (2014). Adaptado pelos autores.

Para esse grupo de atividade, cabe destacar a expressiva geração de empregos e sua classificação como sendo de função mista. Isso porque os produtos e serviços que são oferecidos nessas atividades atendem à demanda da população dos municípios de Capão da Canoa e Xangri-lá, assim como as pessoas que circulam entre as duas cidades para procurar trabalho e produtos de suas necessidades.

\subsection{Serviços em geral}

No grupo de serviços em geral, encontram-se os principais serviços da área médica que, na sua maioria, são prestados no município de Capão da Canoa. No caso de especialidades, atende também à população da cidade de Xangri-lá. Dessa forma, classifica-se como função mista.

Já os serviços de educação têm sua maioria concentrados em Capão da Canoa. Neste caso, cabe destacar que o ensino superior divide-se entre Capão da Canoa, Osório e Torres, pois a proximidade permite buscar esse serviço em outras localidades.

Apresenta-se, na página seguinte, o Quadro 6 (Emprego em Serviços Especializados). 
Quadro 6 - Emprego em Serviços Especializados

\begin{tabular}{|l|c|c|c|c|}
\hline \multicolumn{1}{|c|}{$\begin{array}{c}\text { Síntese das } \\
\text { atividades }\end{array}$} & $\begin{array}{c}\text { Capão da } \\
\text { Canoa }\end{array}$ & $\begin{array}{c}\text { No Empregos } \\
\text { Capão da Canoa }\end{array}$ & $\begin{array}{c}\text { No } \\
\text { Empregos } \\
\text { RS }\end{array}$ & Classificação \\
\hline Serviços de Saúde & 0,69 & 442 & 141.072 & Função Mista8 $^{8}$ \\
\hline $\begin{array}{l}\text { Serviços de } \\
\text { Educação }\end{array}$ & 0,63 & 208 & 72.092 & Função Mista \\
\hline $\begin{array}{l}\text { Serviços para } \\
\text { Famílias }\end{array}$ & 0,35 & 104 & 65.142 & $\begin{array}{c}\text { Consumo } \\
\text { Reflexo }\end{array}$ \\
\hline $\begin{array}{l}\text { Serviços às Famílias } \\
\text { e Empresas }\end{array}$ & 0,79 & 364 & 100.925 & $\begin{array}{c}\text { Genérico } \\
\text { Reflexo }\end{array}$ \\
\hline $\begin{array}{l}\text { Serviços e } \\
\text { Organizações Sociais }\end{array}$ & 0,56 & 128 & 50.021 & $\begin{array}{c}\text { Genérico } \\
\text { Reflexo }\end{array}$ \\
\hline $\begin{array}{l}\text { Serviços de Utilidade } \\
\text { Pública }\end{array}$ & 0,96 & 79 & 17.936 & $\begin{array}{c}\text { Genérico } \\
\text { Reflexo }\end{array}$ \\
\hline $\begin{array}{l}\text { Atividades } \\
\text { Indeterminada }\end{array}$ & 0,37 & 62 & 36.930 & Indeterminado \\
\hline
\end{tabular}

Fonte: Ministério do Trabalho (2014). Adaptado pelos autores.

Outros serviços com forte representatividade são os oferecidos pelos bancos (com carteira comercial), serviços sociais, Caixa Econômica Federal (FGTS e Habitação), também com função mista, pois atende a população local e os turistas visitantes. Por fim, concentram-se as principais atividades e sua empregabilidade no município de Capão da Canoa, destacando que muitas atividades têm relação com a demanda de Xangri-lá. Isso pode ser explicado pela sua originalidade e ainda dependência, apesar de sua emancipação em alguns produtos e serviços. Dessa forma, tem-se Capão da Canoa como referência.

A proximidade entre os dois municípios carrega outra característica com relação ao emprego, pois a população de Xangri-lá tem mais opções de emprego em Capão da Canoa. Isso não impede que o contrário também aconteça, uma vez que duas atividades são marcadas por essa característica: o comércio e a construção civil. Esta última se dá, principalmente, nos condomínios horizontais fechados.

Finalizada a apresentação das atividades no município, cabe destacar que, para o desenvolvimento regional do litoral e especificamente da cidade de Capão da Canoa, devem ser seguidos estudos sobre as atividades com maior relevância na economia da cidade e identificação da potencialidade do surgimento de novos investimentos na região por parte de outras indústrias e ações públicas, garantindo a ocupação de uma grande parcela de pessoas não ocupadas. Paiva (2004, p. 131) descreve que o ponto de partida para ações públicas para o desenvolvimento regional "[...] é um diagnóstico das potencialidades e dos estrangulamentos" nos diversos

${ }^{8}$ As atividades classificadas como mistas atendem tanto à demanda de não domiciliados (turistas), quanto às demandas locais (moradores) (PAIVA, 2015). 
setores e territórios. Portanto, é necessário compreender a dinâmica do mercado identificando suas fragilidades.

A maior produtividade é das empresas locais, e o desenvolvimento de atividades econômicas é voltado para o lazer e o turismo, mesmo com sua característica sazonal. Ressalta-se que, quando o município oferecer outros atrativos, poderá superar a sazonalidade durante a baixa temporada. Cabe destacar que os esforços devem estar focados nas atividades econômicas consideradas propulsivas da economia local e não somente nas reflexas, como comércio a varejo e serviços diversos. Devem-se considerar as atividades propulsivas do território, pois, conforme Paiva (2015), se a qualificação empresarial focar seus esforços somente nas atividades reflexas, sua alavancagem no mercado pode ser relativamente pequena.

\section{Considerações finais}

O crescimento demográfico e o desenvolvimento do mercado imobiliário da cidade de Capão da Canoa podem ser caracterizados como um dos motivos da intensa urbanização dessas cidades. Além disso, são responsáveis pela visível modificação da paisagem natural de balneário, para uma paisagem totalmente urbanizada entre o mar e a lagoa, verificada, principalmente, nos últimos 20 anos.

De acordo com o objetivo deste estudo, que foi o de identificar as principais atividades econômicas no município de Capão da Canoa (RS), e com base no número de empregos gerados, de acordo com os dados da RAIS, pode-se concluir que o turismo sazonal, mesmo não sendo o segmento que mais gera empregos (turismo e lazer), foi o que marcou a ocupação do litoral de forma geral, sendo o grande responsável pelo desenvolvimento do município, pois impulsionou outras atividades, como, por exemplo, as da construção civil, que é a responsável pelos empregos gerados durante a baixa temporada, e outras ligadas diretas ou indiretamente com a construção civil. O estudo também permitiu fazer uma análise dessas atividades, destacando a importância de cada uma delas, de forma sintetizada e hierarquizada, ressaltando suas potencialidades e possíveis fragilidades com o objetivo de contribuir para os estudos da área do desenvolvimento regional.

É importante destacar que o processo de urbanização que ocorreu ao longo do tempo, por meio da construção do novo produto imobiliário referente aos condomínios horizontais e também aos edifícios residenciais, refletiu em uma nova imagem do litoral gaúcho, principalmente na cidade de Capão da Canoa, mudando a paisagem natural pela dinâmica da urbanização. O setor contribui fortemente para o crescimento da economia da região com a geração de emprego nas cidades, pois esta é a atividade que mais emprega mão de obra na região.

Por outro lado, a evolução do processo de urbanização das cidades impacta também a demanda de outros produtos e serviços reflexos dessa atividade, como, por exemplo, serviços públicos como educação, saúde e tratamento de água e esgoto; mobilidade urbana e habitação para a população mais vulnerável, levando os municípios a acumular problemas com demandas sociais. Por outro lado, o consumo de produtos e serviços na cidade, como alimentação em geral, vestuário e calçados, 
também demandam especialização das empresas.

Por fim, é importante destacar que o desenvolvimento econômico do litoral está diretamente ligado ao turismo e à construção civil, mas se deve respeitar a legislação local em relação à ocupação do solo, o zoneamento ambiental e as demais legislações ambientais, valorizando as belezas naturais. Para tanto, o Poder Público deve suportar a pressão vinda do setor imobiliário, por meio de empresas privadas com interesse local, no intuito de estabelecer um equilíbrio entre desenvolvimento econômico e preservação dos recursos naturais, garantindo não só a qualidade de vida, que tanto atrai os investimentos na região, mas também o desenvolvimento regional sustentável.

\section{Referências}

ATLAS DO DESENVOLVIMENTO HUMANO NO BRASIL. Disponível em: <http://www. atlasbrasil.org.br/2013/pt/perfil_m/capao-da-canoa_rs\#demografia>. Acesso em: 5 abr. 2015.

BONAMENTE, Jorge Luis; SOUZA, Arildo João de. Planejamento Urbano e Ambiental. Indaial: Uniasselvi, 2012.

CAMARGO, J. M. Flexibilidade e produtividade do mercado de trabalho brasileiro. In:__. (Org.). Flexibilidade do mercado de trabalho no Brasil. Rio de Janeiro: Fundação Getúlio Vargas. 1996. Disponível em: <http://www.scielo.br/scielo. php?pid=S1413-80502008000300001\&script=sci_arttext\&tlng=pt>. Acesso em: 19 maio 2015.

COREDE LITORAL. Disponível em: <http://www.fee.rs.gov.br/perfil-socioeconomico/ coredes/detalhe/?corede=Litoral>. Acesso em: 28 maio 2015.

FAMURS. Federação das Associações dos Municípios do Rio Grande do Sul. Guia das Associações de Municípios. Disponível em: <www.famurs.com.br>. Acesso em: 22 nov. 2014.

IBGE. Instituto Brasileiro de Geografia e Estatística. Disponível em: <http://cidades. ibge.gov.br/xtras/perfil.php?lang=\&codmun=430463\&search=rio-grande-dosul| capao-da-canoa>. Acesso em: 28 abr. 2014.

MORAES, Jorge L. A. de. Capital Social e Políticas Públicas para o Desenvolvimento Regional Sustentável. 2003. Disponível em: <http://www.ecoeco.org.br/conteudo/ publicacoes/encontros/v_en/Mesa2/4.pdf>. Acesso em: 31 maio 2015.

MINISTÉRIO DO TRABALHO. Relação Anual de Informações Sociais (RAIS). Disponível em: <http://trabalho.gov.br/rais>. Acesso em: 28 maio 2015.

PAIVA, Carlos A. Como identificar e mobilizar o potencial de uma região para o desenvolvimento endógeno. Porto Alegre: Fundação de Economia e Estatística (documento FEE no 59). 2004. Disponível em: <http://www.fee.tche.br/sitefee/ download/documentos/documentos_fee_59.pdf>. Acesso em: 30 abr. 2014. 
. Termo de referência para a implantação de políticas de Desenvolvimento Econômico Regional baseadas nas particularidades produtivas dos territórios. Disponível em: <http://www.agdi.rs.gov.br/upload/1417689275_Termo\%20de\%20 Refer\%C3\%AAncia\%20Sebrae.pdf>. Acesso em: 28 maio 2015.

PINENT, Maximilianus Andrey Pontes. A Expressão Econômica do Turismo em Sistemas Alternativos de Mensuração da Geração Direta e Indireta de Emprego e Renda: um estudo empírico sobre o litoral norte gaúcho do Rio Grande do Sul. Disponível em: <https://www2.faccat.br/portal/sites/default/files/ disserta\%c3\%a7ao-maximilianusjan2016_paiva.pdf>. Acesso em: 9 maio 2016.

PNDU. Plano Nacional de Desenvolvimento Urbano. 2004. Disponível em: <http://www.unc.br/mestrado/mestrado_materiais/1PoliticaNacional DesenvolvimentoUrbano.pdf>. Acesso em: 1 maio 2015.

RAMOS, Alexandre Costa. Fatores de atração migratória no litoral norte do Rio Grande do Sul e o desenvolvimento regional: um estudo a partir dos municípios de Capão da Canoa e de Osório. 2014. Disponível em: <http://btd.unisc.br/ Dissertacoes/AlexandreCosta.pdf>. Acesso em: 28 maio 2015.

SCHEFFER, Alceu de Matos. Desenvolvimento regional no litoral norte do Rio Grande do Sul: o caso do turismo no município de Torres/RS. 2010. Disponível em:

<http://btd.unisc.br/Dissertacoes/AlceuScheffer.pdf.>. Acesso em: 10 out. 2014.

SESSEGOLO, Ricardo Antunes. Novas possibilidades de crescimento para a construção civil. Revista Universo da Construção. Porto Alegre, n. 4, p. 49, fev. 2014.

SOUZA, Mariana Barbosa de. Urbanização e segregação socioespacial na Região do Litoral Norte do Rio Grande do Sul: uma análise da expansão e da (I)legalidade dos condomínios horizontais residenciais. 2013. Disponível em: <http://btd.unisc.br/ Dissertacoes/MarianaSouza.pdf>. Acesso em: 10 out 2014. 